Article

\title{
Students' Perceptions of Interdisciplinary Coursework: An Australian Case Study of the Master of Environment and Sustainability
}

\author{
Jessica K. Abbonizio and Susie S. Y. Ho *(D) \\ Faculty of Science, Biological Sciences, Monash University, Level 125 Rainforest Walk, Clayton Campus, \\ Clayton, Melbourne, VIC 3800, Australia; jabb0003@student.monash.edu \\ * Correspondence: susie.ho@monash.edu; Tel.: +61-3-9905-9782
}

Received: 13 August 2020; Accepted: 20 October 2020; Published: 27 October 2020

check for updates

\begin{abstract}
Over the past decade we have seen a global increase in interdisciplinary sustainability degrees. These degrees are relatively understudied due to their recent emergence. To better understand the challenges and benefits of this type of coursework and learning experience, we must explore students' perspectives. Rarely explored from the student viewpoint are: (1) highly interdisciplinary instruction that transcends more than four disciplines; (2) the potential effect of students' incoming disciplinary background. This case study seized an opportunity to gain insights and perceptions from students across very diverse backgrounds within a shared interdisciplinary program. We surveyed 61 students enrolled in a highly interdisciplinary degree (Master of Environment and Sustainability; Monash University, Melbourne, Australia) and compared responses of students from STEMM, non-STEMM and mixed incoming degrees. Students' specific disciplinary backgrounds were diverse, including physical sciences, engineering, marketing, business, fashion, law and education. We used a mixed methods approach to analyze survey data. The dominant perceived benefits of interdisciplinary training reported were: (1) career relevance; (2) expanded knowledge and perspectives of sustainability issues; (3) confidence in envisioning sustainability solutions. The main perceived challenges reported were potential confusion from rapidly upskilling into new domains and disciplinary jargon. Interestingly, respondents in this case study viewed these challenges as an authentic reflection of professional sustainability practice rather than a pedagogical issue. In line with this, students showed a preference for pedagogical approaches that simulated real world scenarios and developed career skills. Disciplinary background did not generally influence students' views. All students identified similar challenges, benefits and pedagogical preferences, with one difference. Students from mixed prior degrees and non-STEMM disciplines showed a possible trend towards valuing cross-disciplinary teamwork more than those from STEMM backgrounds. Overall, our findings suggest that the diverse student cohort within the highly interdisciplinary sustainability program of this case study generally viewed this mode of education as beneficial, career-relevant and accessible. This case study may additionally encourage interdisciplinary educators from other fields, such as health professions, to also include more diverse domains and student cohorts in their programs.
\end{abstract}

Keywords: interdisciplinary education; accessibility; sustainability education; student perspectives; postgraduate; STEMM; pedagogy; challenges; employability; teamwork

\section{Introduction}

Higher education has evolved from traditional siloed monodisciplinary approaches towards more interdisciplinary instructional styles that synthesize knowledge, perspectives and values across 
curricula domains [1]. Interdisciplinary programs are becoming more prevalent in higher education [2,3]. For example, interdisciplinary education is increasingly common in health professions [4], big data and cultural studies [3], and in sustainability education [5]. This case study focused on interdisciplinary coursework in a sustainability education context. An interdisciplinary approach lends itself to the multifocal examination of complex and intractable issues, such as climate change and water security. It is also solution-focused, encouraging students to address complex social problems [6]. The main aim of this case study is to explore students' perspectives to better understand the accessibility, experiences and perceptions of interdisciplinary coursework to diverse learners in a sustainability context. Sustainability, or sustainable development, is often defined as "development that meets the needs of the present without compromising the ability of future generations to meet their own needs" [7] (p. 43). Sustainability is an area featuring complex problems that span economic, social and environmental spheres, typically without simple solutions [8]. There have been international calls for the uptake of interdisciplinary education in sustainability and environmental fields for decades. For example, the 1970s Tbilisi Declaration explicitly set interdisciplinary guidelines and goals for environmental education [5]. Since then, environmental and sustainability education have become some of the most well recognized interdisciplinary instructional fields today [9].

In spite of this upward trend, research has commonly neglected students' perspectives and has therefore left a gap in our knowledge of students' perceptions, experience and the accessibility of interdisciplinary instruction. Some concerns in the literature are that this mode of education may lack clarity and add unnecessary cognitive burden on students. These concerns are typically expressed from the academic perspective $[9,10]$, though they also feature in limited literature from students' viewpoints [11]. In particular, there are few studies of students' perspectives of highly interdisciplinary postgraduate courses fusing multiple disciplines. Very few studies have examined whether a student's disciplinary background affects their experience or perceptions of navigating four or more disciplines (which we are terming a highly interdisciplinary experience), and is therefore a core focus of this study.

The present case study revealed that students from diverse disciplinary backgrounds perceived a wide range of similar benefits of interdisciplinary sustainability training, including both expanded and work-relevant skills and knowledge. In terms of potential added cognitive burden, students did report possible confusion and challenges associated with interdisciplinary education at times. These challenges were, however, viewed as positive and authentic steppingstones in preparation for sustainability practice in future careers. Students reported it was important to gain skills and experience in navigating different disciplines and complex issues. Overall, students from different disciplinary backgrounds reported similar perceptions, except for possible differences in the value of teamwork. This suggests that the common interdisciplinary learning approaches used in education and employed in the degree that is the focus of this case study appear suitable for diverse cohorts. Below, we provide more background on interdisciplinary pedagogy, outline the status of the existing literature and key knowledge gaps, and introduce the highly interdisciplinary program explored in this case study.

\subsection{Interdisciplinary Pedagogy and Its Career Relevance}

Interdisciplinary pedagogy has many definitions depending on the educational context, however, the deep integration of knowledge and ideas across disciplines is a typical feature [1]. For the purposes of this case study, we are using the term "highly interdisciplinary" as distinct from less integrative "multidisciplinary" or "multisubject" approaches (more common in liberal arts degrees, for example), which are not explored here. Interdisciplinary pedagogy is recognized as highly valuable in sustainability, as are the related transdisciplinary, systems thinking and knowledge weaving approaches [12-14]. Each of these integrative, pluridisciplinary approaches aims to synthesize disciplines to varying extents for a more holistic and complex educational experience and worldview $[1,12,13,15]$. Traditionally, relatively few interdisciplinary educational programs have included the breadth of domains or length of training appropriate for deeply embedding these 
integrative approaches. This breadth and length are, however, necessary for students to better understand multidimensional and interconnected sustainable development issues [16]. Instead, many interdisciplinary orientated or soft skills programs have tended to be short modules embedded or added onto monodisciplinary courses [17-19]. Dale and Newman [16] have indicated, however, that the greater and deeper integration of a wider spectrum of disciplines can offer a more holistic and career-relevant curriculum.

The interdisciplinary programs of today are becoming more complex in synthesizing and integrating more disciplines. Many newer programs, such as that of the present case study, are far more ambitious in integrating four or more domains or disciplines, including areas such as international development, advocacy, leadership, science, governance, law and business. This is achieved through the collaborative development of curricula across faculties and industries [20]. This ambition and complexity in sustainability course design are necessary in preparing graduates for their careers. Future sustainability practitioners working in authentic contexts, such as initiatives under the United Nations' (UN) Sustainable Development Goals (SDGs) within corporate, UN agencies, government or NGO organizations will require the knowledge and skills to collaborate across professional sectors and national boundaries. Interdisciplinary pedagogical approaches that support sophisticated intercultural, teamwork, negotiation and communication skills, as well as cross-disciplinary fluency are therefore crucial [21]. The need for these graduate competencies is recognized by the UN and a range of employers [5,21-23]. There are also more and more roles in nexus spaces, such as between science and policy or business and government, that appeal to future leaders and are best supported by more interdisciplinary curricula [23].

The merging of curricula in interdisciplinary teaching and learning in sustainability should aim to develop students' knowledge and skills to make informed decisions and expand their cross-sector literacy for their future careers. Interdisciplinary learning often focuses on the development of transferable so called "21st century" interpersonal and cognitive skills. These aptitudes should help equip sustainability graduates to approach issues from complex social, economic and environmental perspectives [6]. For instance, most graduates will require critical thinking skills to interpret, integrate and synthesize diverse information from many sectors, evaluate social and ecological crises using sustainability science or weaving methods [14], and form well rounded perspectives [5,24]. Sustainability graduates will often need to produce, synthesize and use different forms of evidence and arguments for effective and ethical decision making. They must also communicate effectively across different cultural contexts, with an appreciation for various types of evidence, worldviews and stakeholder perspectives. Such learning outcomes are thought to be achieved through interdisciplinary pedagogic tools, such as thematic teaching [1], experiential and active learning (i.e., problem- and project-based tasks) [25-28], collaborative learning (i.e., teamwork and peer led learning) [25,29,30], and reflection tasks [31]. Overall, interdisciplinary curricula and pedagogy endeavors to prepare students for approaching genuine multidimensional global issues and professional landscapes [3].

\subsection{Research into Interdisciplinary Education: What Are the Gaps?}

While the argument for interdisciplinary education is clear, there are few studies that explore interdisciplinary learning from students' perspectives. This is particularly true of contemporary interdisciplinary degrees that integrate four or more domains (e.g., policy, science, engineering and business). These newer programs often meld many disciplines and feature the collaborative co-development of curriculum across diverse educational teams. Most of the existing literature, however, has focused on examining single interdisciplinary units embedded in predominantly monodisciplinary degrees $[18,19,32]$. It is important, though, to also focus on highly integrated longer duration courses and training since they have been touted as the future of higher education [3]. Students' experiences and perceptions of such training are little known. The lack of research on more integrated and multi-year programs may in part result from their recent emergence as well as the complexity of exploring students' perceptions of such programs. The issue is that students may enter interdisciplinary training 
from a twider range of disciplinary backgrounds than usually seen in monodisciplinary settings [20]. Students' experiences and perceptions of these integrated programs may, therefore, be wide ranging and thus important to understand. As such, students may experience different individual and disparate learning trajectories [33], and potentially glean very different meanings and learnings from activities than their peers. Interdisciplinary educators and course designers therefore face a unique challenge, as do those studying students' experiences, perceptions and graduate outcomes.

The literature on students' experiences and perceptions is lacking relative to institutional perspectives [34]. Research into interdisciplinary education has often focused on educators' perspectives, institutional barriers and course design [35-38]. Indeed, it is important to investigate the mechanisms to support collaborative cross-faculty course design. Students' viewpoints should, however, also be central since they are important educational stakeholders capable of providing insights into their experiences and perceptions of integrated programs. Further, students' willingness to actively contribute to education is illustrated by student led sustainability projects and workshops in universities [39]. Students' perspectives and learning experiences are routinely surveyed in health professions education [40] and deserve the same consideration in sustainability contexts. Students' voices are especially important in interdisciplinary programs where educators must consider diverse cohorts and many different learning trajectories simultaneously [33]. Students are also the beneficiaries of our programs. As future sustainability leaders, students should have the opportunity to comment upon their perceptions, learning experiences, accessibility of content and activities, career relevance and skills development for making positive change in society. We further argue that interdisciplinary education is an inherently collaborative practice. Scholars and educators can further embody this participatory ethos by including student voices to understand how such programs are experienced and perceived. The rare studies that have explicitly surveyed interdisciplinary students' perceptions have typically investigated relatively short-term programs, spanning a week to a year $[17,34]$. These studies often look at secondary [34] or undergraduate contexts [19,24,32,41]. This interdisciplinary training is also typically embedded or "bolted-on" within a larger degree or program and may only integrate two to three disciplines. Students in such studies may therefore often come from a relatively monodisciplinary background in comparison to some newer degrees. It is rare to find a cohort from a broad range of distinct backgrounds to gain insights from different perspectives within a shared postgraduate interdisciplinary program. Curriculum design and pedagogical studies are also typically biased towards one domain, such as engineering, science or political science. More studies on students' perceptions of highly integrated, longer duration postgraduate programs and the accessibility and relevance to diverse learners are therefore needed.

\subsection{Exploring Postgraduate Students' Perceptions of Highly Interdisciplinary Sustainability Coursework through an Australian Case Study}

This case study explored the experiences and perceptions of students enrolled in a highly integrated two-year coursework program, namely the Master of Environment and Sustainability (MES; Monash University, Melbourne, Australia). This degree was co-developed across six disciplines in 2017 and innovatively integrates arts, science, sustainable development, business and economics, international development, governance and policy. The MES is aligned to all 17 SDGs [42] and provided a valuable opportunity for exploring the perceived benefits and challenges of a newer style of more complex and highly integrated co-developed curriculum. Since the MES melds many disciplines, and extends over two years, it may be that the challenges and benefits of interdisciplinary instruction become more apparent to students than to those taking short or add-on programs. Importantly, the MES cohort is extremely diverse, welcoming students from all undergraduate degree areas and 45 different countries. This case study may therefore unearth more nuanced findings on diverse student experiences and perceptions of interdisciplinary education and how students' prior degrees may inform their perceptions.

The objective of this case study was to survey postgraduate students' perceptions of highly integrated interdisciplinary sustainability coursework. We aimed to explore diverse students' views on 
the benefits, challenges, and pedagogies more common in interdisciplinary rather than monodisciplinary curricula. We also aimed to understand whether students' perceptions were influenced by their incoming disciplinary background. Preliminarily exploring and mapping students' perceptions may offer educators more insight into how these new interdisciplinary programs are perceived and experienced. Our findings may also support interdisciplinary educators from a range of fields, such as health professions and engineering, to consider incorporating more domains and welcome more diverse student cohorts into their programs. Our main research question was:

- How do postgraduate students perceive highly integrated interdisciplinary coursework?

To answer our main question, we explored the following sub questions:

- What are the dominant benefits perceived by students, and what is the perceived duration of these benefits?

- What are students' perceptions of common interdisciplinary pedagogical approaches?

- What are students' perceptions of the dominant challenges?

- Are there differences in perspectives between students from different incoming disciplinary fields, which may affect the accessibility of the coursework?

\section{Materials and Methods}

\subsection{Methodology}

This case study used a concurrent mixed-methods design involving the collection and analysis of quantitative and qualitative responses from a voluntary online survey. This approach was used to gain an in depth understanding of students' perceptions. Quantitative survey items were relatively easily completed by participants and designed to optimize response rates [43]. Qualitative data added a more nuanced understanding of the quantitative data and helped to triangulate quantitative responses [44].

\subsection{Survey Design and Distribution}

The unique survey used was informed by a range of previous studies and existing survey instruments in the science and sustainability education literature $[11,32,33]$. The survey was largely based upon a validated and commonly used instrument in interdisciplinary health professions education known as the Readiness for Interprofessional Learning Scale (RIPLS) [45]. Quantitative data were gleaned from five-point Likert scales (strongly disagree to strongly agree) [46]. Qualitative data were collected from open response items [47]—for example "Please indicate the reason for your response" to each Likert scale statement and "If you have any general comments or opinions on whether there are any potential value or benefits to interdisciplinary education, please comment here". The survey comprised 26 items and took approximately 15-20 $\mathrm{min}$ to complete. The first section of the survey collected demographic data (i.e., age, gender, professional experience and disciplinary background). The bulk of the survey focused on students' perceptions of the potential value and benefits, pedagogical approaches and challenges of interdisciplinary education. The optional survey asked students about their learning experiences and perceptions of interdisciplinary education generally, rather than about the specific MES course or its subjects. The survey instrument was created and distributed via SurveyMonkey (SurveyMonkey Inc., Palo Alto, CA, USA). Students were invited to participate via email, online announcements through a learning management system and social media. All subjects gave their informed consent for inclusion before they participated in the study. The study was conducted in accordance with the Declaration of Helsinki, and the protocol was approved by the Monash University Human Research Ethics Committee in May 2019 (MUHREC Project ID 20013).

\subsection{Target Course and Participants}

The survey was open to Monash University students enrolled in the MES. The interdisciplinary curriculum of the MES was co-developed across the faculties of science, social science, business 
and economics as well as the Monash Sustainable Development Institute, with insights from other fields. MES students take two explicitly interdisciplinary foundation units (i.e., Global Challenges and Sustainability ENS5010 and Perspectives on Sustainability ENS5020), which is equivalent to a full semester. While the MES is predominantly coursework based, students also take the equivalent of an additional full semester in advanced experiential interdisciplinary capstone units. These capstones offer students a choice between a research thesis, industry consultancy project, or an internship. Half of the two-year MES curriculum is therefore wholly interdisciplinary. Additionally, the MES has five specialization streams (detailed below). The specialization units themselves and elective options, forming the additional year of the course, are also interdisciplinary but to a lesser extent.

Overall, the survey received 61 responses (the response rate was $27 \%$ with 230 students enrolled in the degree). The sample included students in their first year (41\%) or second and final year (31\%) as well as commencing students ( $28 \%)$. To highlight the diversity in the cohort, participants were taking the following specializations (noting students can choose more than one): Environmental Security (26\%), Corporate Environmental and Sustainability Management (26\%), Leadership for Sustainable Development (26\%), Environment and Governance (21\%), and International Development and Environment (7\%), while 10\% were still deciding on their specialization. Since this case study focused on students' incoming disciplinary backgrounds, differences between year levels and MES specializations were not analyzed. Almost all students were studying full time (90\%). Most respondents had no prior interdisciplinary education before entering the degree $(77 \%)$. Participants were largely aged $21-25$ years (54\%), with a minimum and maximum age of 21 through to $66+$ years. The sample comprised more women (62\%) than men, as seems common in sustainability programs [48].

The cohort was highly diverse in relation to many factors, including discipline, age and culture as well as professional experience. This case study was chosen for this reason, given our focus on diverse learners and their perceptions of interdisciplinary instruction. Differences associated with age, cultural identity and professional experience were not assessed in the present study due to the unequal sample sizes in the dataset for these subgroups. For demographic context, however, the majority of respondents had between $0-5$ years of incoming professional experience ( $75 \%$ ). Professions included academia, teaching, retail, construction, natural resource management, conservation, fashion, architecture, communications, marketing, advertising, manufacturing, and engineering consultancy. The sample also featured 18 different cultural identities from Australia (43\%), India (16\%), China (10\%), Bangladesh (4\%), Mexico (3\%), Taiwan (3\%), Botswana (3\%), Singapore (3\%), Denmark (1\%), Ecuador $(1 \%)$, Saudi Arabia (1\%), Thailand (1\%), Colombia (1\%), Vietnam (1\%), Brazil (1\%), Sierra Leon (1\%), Malaysia (1\%) and Pakistan (1\%).

In terms of disciplinary background, students entered from previous degrees across STEMM (science, technology, engineering, mathematics and medicine; 46\%) and non-STEMM areas (humanities and social sciences; $43 \%$ - e.g., history, geography, governance, law, economics and business). A smaller proportion were from mixed incoming degrees (including double degrees), which spanned both STEMM and non-STEMM fields (11\%). A detailed breakdown of students' incoming degrees is explored in Section 3.4. To analyze any potential influence on students' perceptions, students' incoming degrees were assigned to broad STEMM, non-STEMM and mixed categories according to the Australian Standard Classification of Education [49] for the purposes of increasing statistical power.

\subsection{Data Analyses}

Quantitative data (Likert scale responses) were analyzed and presented as summary statistics, including means, standard error and percentage of agree or strongly agree responses. We also used a single-factor non-parametric analysis of variance (ANOVA) to determine any statistical differences in responses to each survey item between students': (1) broad disciplinary backgrounds (STEMM, non-STEMM and mixed prior degrees); (2) gender (man, woman or non-binary/self-described). The ANOVA significance threshold was set to 0.05 [50], and where necessary a paired sample $t$-test with Bonferroni correction (to adjust for multiple comparisons) was used determine which demographic 
data were significantly different from each other [51]. Where no significant differences were evident, data were pooled. There were no significant differences found between genders (and thus this element of the study is not detailed). Further, generally no significant differences were apparent between disciplinary backgrounds, with the exception of pedagogy as detailed in the results.

Thematic analysis was applied to the qualitative data (open ended responses) through open coding of emerging dominant thematic nodes and sub nodes [52], using NVivo (QSR International Ltd., Chadstone VIC, Australia, Version 12.6.0, 2019). Common themes were distilled through notetaking, reading and re-reading of each response. Students' quotes are presented in the results with codes that indicate the respondents' diversity, including disciplinary background, gender, year level and specialization in the MES.

\section{Results}

\subsection{Perceived Benefits of Interdisciplinary Sustainability Education}

As expected from a self-selected cohort, all respondents in this case study agreed that interdisciplinary sustainability education is valuable and beneficial $(100 \%$ agreement; $n=61)$. Of the 228 open responses to survey items on the benefits of interdisciplinary education, three general themed perceptions emerged across responses from all incoming backgrounds, namely: (1) career relevance, including cross-sector communication and collaboration skills $(38 \% ; n=86)$; (2) cognitive benefits including expanded worldviews, knowledge acquisition and diversification as well as critical thinking $(30 \%)$; (3) confidence in envisioning innovative solutions to address complex issues (29\%; Table 1).

Table 1. Thematic analysis of students' qualitative responses to survey items on the perceived benefits of interdisciplinary education. General themes and their associated specific themes are presented.

\begin{tabular}{cl}
\hline General Themes & \multicolumn{1}{c}{ Specific Themes } \\
\hline \multirow{2}{*}{ Career relevance } & Cross-sector communication, engagement and collaborative skills \\
& Appreciation of others' professional roles and expertise \\
& Networking and relationship building opportunities \\
\hline \multirow{3}{*}{ Cognitive benefits } & Deepened understanding of sustainability issues \\
& Broadened perspectives and worldviews \\
& Knowledge acquisition and diversification \\
& Critical thinking skills \\
\hline \multirow{2}{*}{ Sustainability solutions } & Confidence in envisioning innovative solutions to address complex \\
& sustainability issues \\
\hline
\end{tabular}

Starting with career relevance, respondents from diverse disciplinary backgrounds cited the perceived benefits of learning about interprofessional collaboration and synergies (21\%), appreciation of others' professional roles and expertise $(10 \%)$, and networking opportunities $(1 \%)$. Illustrative responses, from students from different backgrounds, included:

Having to learn to work with people from different backgrounds who have been trained in different ways, and to lean on people with different expertise from me, has been valuable. -STEMM, woman, second year, Leadership for Sustainable Development

Education with people from other disciplines—such as in the MES-puts you in touch with people who may be able to help you in such a way in future, or who may know someone else who may be able to help in future. - Mixed prior degree, woman, second year, Leadership for Sustainable Development

[Interdisciplinary education] is like training for future jobs, because when we have to work, we need to be a team member not an individual. -STEMM, woman, second year, Environmental Security 
Students also reportedly valued learning about stakeholder and decision-maker engagement $(15 \%)$, encapsulated in the following responses:

In future careers [interdisciplinary education] could be a beneficial pathway to already have an experience in dealing and working with a range of stakeholders. -STEMM, man, second year, Environment and Governance

Exposure to people with different mindsets and experience allows learning how to negotiate. -STEMM, man, commencing student

[Interdisciplinary education] makes people understand the evidence behind the critical emerging issues and [helps us] guide policy makers to have an evidence based decision making approach. —STEMM, man, first year, Environmental Security

A further $8 \%$ of these responses also articulated the benefits of developing communication skills and fluency in a variety of professions, demonstrated in the following responses:

Learning to [communicate] with multi-disciplinary language helps building robust relationships between professionals due to the mastering of comprehensive skills and ability to engage multi-perspective conversation. -STEMM, man, second year, Corporate Environmental and Sustainability Management

[Learning about] reading and writing for a large audience who may not be well versed with the topic helps [you crystalize] knowledge and write about the relevant and important points in a way that is understandable to all. - Mixed prior degree, woman, commencing student

Additionally, respondents cited a range of general perceived cognitive benefits (30\%), including broadened perspectives $(18 \%)$, deepened understanding of complex sustainability issues $(10 \%)$, knowledge acquisition and diversification (8\%), and critical thinking skills (5\%). Representative responses included:

Working with a range of people, learning from their experiences and engaging with diverse perspectives could potentially enhance one's ability to either narrow down or broaden their horizon to understand the holistic picture. -non-STEMM, man, second year, Environment and Governance

Most valuable was the big picture view of all the matters affecting sustainability in the world. By understanding this, I can see where my part fits in a broader context. -STEMM, woman, first year, Corporate Environmental and Sustainability Management

[Interdisciplinary education] has increased my horizons of thinking and given me tools to get out of monotonous thinking and have developed ability understanding of sustainability issues in multiple arrays. -STEMM, woman, first year, Environmental Security

Finally, students across a range of disciplinary backgrounds perceived that interdisciplinary education would ultimately support them in envisioning innovative solutions to complex sustainability issues (29\%). This theme was highlighted in the following responses:

I will graduate as a professional that embraces diversity of knowledge and utilise this to [analyze], articulate, construct and develop critical solutions to global challenges. - STEMM, man, first year, Environment and Governance

Complex sustainability problems require complex solutions and it takes individuals with the ability to consider several perspectives to come up with these solutions. -STEMM, woman, first year, Environmental Security 
I am even more aware of the limitations of my discipline but also its advantages. I am able to help find the linkages between two disciplines as well to solve the issue. - non-STEMM, woman, first year, Environmental Security

[We] can use the advantages of various disciplines, complement each disciplines' advantages to achieve the best results, "one plus one is greater than two". - STEMM, woman, commencing student

The quantitative survey data below further supported these open responses (Table 2). Students from all disciplinary backgrounds in this case study reportedly valued the perceived professional skills and development afforded by interdisciplinarity. Specifically, students perceived that interdisciplinary education would help them become more effective sustainability professionals ( $94 \%$ agreement; $n=57$ ) and develop important professional cross-sector relationships (93\%). Students agreed with valuing other tasks and experiences linked to employability, such as communicating with broad audiences $(96 \%)$ and working in teams $(90 \%)$. The vast majority of respondents also agreed that interdisciplinary education broadens students' perspectives of sustainability issues (95\%), encourages critical thinking $(94 \%)$ and deepens understanding of a range of disciplines and sustainability issues $(93 \%)$. Students further valued learning to identify others' worldviews $(91 \%)$ and challenging their own personal worldviews (89\%). Thus, knowledge and skills linked to employability, impact and cognitive development appeared important to the respondents as observed in both quantitative and qualitative data. Our preliminary statistical findings did not show substantial differences between STEMM, non-STEMM and mixed prior degree backgrounds here.

Table 2. Students' quantitative responses on the benefits of interdisciplinary sustainability education. Table displays the mean and standard error (SE) of Likert scale values, the percentage of agree or strongly agree responses in parentheses, one-way ANOVA $p$ value comparing broad disciplinary subgroups and the total number of responses $(\mathrm{N})$ for each survey statement.

\begin{tabular}{|c|c|c|c|}
\hline Survey Statement & $\begin{array}{c}\text { Mean } \pm \text { SE 1-5 Likert } \\
\text { Scale (\% Agree or } \\
\text { Strongly Agree) }\end{array}$ & $\begin{array}{l}\text { Disciplinary } \\
\text { ANOVA } p \text { Value }\end{array}$ & $\mathbf{N}$ \\
\hline $\begin{array}{l}\text { Interdisciplinary education will help me communicate better } \\
\text { with other professions after qualification }\end{array}$ & $4.15 \pm 0.17(96)$ & 0.30 & 61 \\
\hline $\begin{array}{l}\text { Sustainability issues ultimately benefit when people from } \\
\text { different disciplines work together }\end{array}$ & $4.22 \pm 0.18(95)$ & 0.43 & 61 \\
\hline $\begin{array}{l}\text { Interdisciplinary education helps broaden my perspective of } \\
\text { sustainability issues }\end{array}$ & $4.18 \pm 0.18(95)$ & 0.35 & 61 \\
\hline $\begin{array}{l}\text { Learning with students from other disciplines will make me a } \\
\text { more effective sustainability professional }\end{array}$ & $4.13 \pm 0.18(94)$ & 0.36 & 61 \\
\hline $\begin{array}{c}\text { Interdisciplinary education helps me develop my critical } \\
\text { thinking skills }\end{array}$ & $4.03 \pm 0.18(94)$ & 0.59 & 61 \\
\hline $\begin{array}{l}\text { Interdisciplinary education increases my ability to understand } \\
\text { sustainability issues }\end{array}$ & $4.07 \pm 0.18(93)$ & 0.22 & 61 \\
\hline $\begin{array}{l}\text { Learning with students from other disciplines will improve } \\
\text { my professional relationships after qualification }\end{array}$ & $4.03 \pm 0.18(93)$ & 0.25 & 61 \\
\hline $\begin{array}{l}\text { Interdisciplinary education helps me understand my own } \\
\text { discipline's limitations }\end{array}$ & $3.90 \pm 0.19(91)$ & 0.24 & 61 \\
\hline $\begin{array}{l}\text { Interdisciplinary education helps me think positively about } \\
\text { other disciplines }\end{array}$ & $4.10 \pm 0.18(91)$ & 0.28 & 61 \\
\hline $\begin{array}{l}\text { Interdisciplinary education has helped me identify other } \\
\text { people's worldview }\end{array}$ & $4.07 \pm 0.17(91)$ & 0.41 & 61 \\
\hline $\begin{array}{c}\text { Interdisciplinary education helps me become a better team } \\
\text { worker }\end{array}$ & $3.97 \pm 0.18(90)$ & 0.62 & 61 \\
\hline $\begin{array}{l}\text { Interdisciplinary education has challenged my own } \\
\text { worldview }\end{array}$ & $3.89 \pm 0.19(89)$ & 0.37 & 61 \\
\hline
\end{tabular}

Notes: Likert scales were quantified as follows: strongly agree (5), agree (4), neither agree nor disagree (3), disagree (2) and strongly disagree (1). 
In terms of the perceived duration of benefits, the majority of students in this case study felt that these (expanded skills, knowledge and views, confidence in envisioning solutions and career relevant benefits) would extend into their careers ahead $(79 \% ; n=48)$, with many also citing these benefits would have lifelong effects $(75 \%)$. Most at least agreed that the benefits would generally last throughout the two-year degree (59\%). Thus, students' perceived benefits of interdisciplinary learning appeared to generally be viewed in terms of career outcomes and lifelong learning, at least for the present case study.

\subsection{Perceptions of Common Pedagogical Approaches of Interdisciplinary Sustainability Education}

As in Section 3.1 on the benefits of interdisciplinarity, student views on pedagogy in this case study were often discussed in terms of career development. Students from all backgrounds appeared to value approaches that were seen as skills based and authentic to the professional landscape. Of the 50 open responses to survey items on pedagogy, students perceived value in three general approaches, namely activities supporting communication development, critical thinking prompts and real world simulations (Table 3).

Table 3. Thematic analysis of students' qualitative responses to survey items on perceptions of common pedagogical approaches in interdisciplinary education. General themes and their associated specific themes are presented.

\begin{tabular}{cc}
\hline General Themes & Specific Themes \\
\hline Activities supporting communication development & Group work and teamwork \\
\hline Critical thinking prompts & Reflection tasks \\
\hline Real world simulations & Project- and problem-based learning tasks \\
\hline
\end{tabular}

Firstly, students across disciplinary backgrounds reportedly appreciated pedagogic approaches that developed communication skills, such as during team-working activities ( $16 \%$ of responses to items on pedagogy; $n=8$ ), with two representative responses noting:

In just one year, I have understood different perspectives in tackling the same problems, and also how to deal with people coming from different backgrounds through effective communication. - non-STEMM, woman, first year, Environmental Security

Learning to speak different disciplinary languages will help us reach across the aisle later in life. -STEMM, woman, second year, Leadership for Sustainable Development

Reflection tasks were also generally perceived positively and featured in $12 \%$ of these responses. Students perceived that reflections supported them to think critically about sustainability issues and consolidate their learning, illustrated by the quote below:

[Reflection tasks] help you deepen your knowledge and challenge your point of view when you rethink what you have learned. -STEMM, man, first year, Environment and Governance

A small number of these responses (1\%), however, raised some doubts about the effectiveness and authenticity of reflection tasks if they were assessed, with one student commenting:

While [reflection tasks] were a great way to engage with the unit, the fact that it was marked meant that there were things expected of me to communicate, even when I may not have felt them or understood that in class. -non-STEMM, woman, first year, Environmental Security

Real world simulations such as project- and problem-solving tasks were also commonly reported as beneficial for deepening students' concrete understanding of genuine sustainability issues $(12 \%)$. Representative responses included: 
[Real world problem-solving tasks] helped me realize that there's no one right direction from a specific discipline, but that it takes solutions from various disciplines to produce a holistic answer. - Mixed prior degree, man, second year, Leadership for Sustainable Development

[Real world problem-solving tasks] simulate what we may expect in the professional working space-non-STEMM, woman, first year, Environmental Security

Yes, the more 'real world' the better. You cannot diminish the complexity of the modern era. -non-STEMM, woman, first year, Leadership for Sustainable Development

[Interdisciplinary education] is very relevant as this is the type of work that will be required in our workplaces, and the skills will be useful not only in our careers but also in our social circles and wider community. - non-STEMM, man, second year, Environment and Governance

Students' responses to Likert scale statements in this case study supported and nuanced the qualitative data (Table 4). It is apparent from the table that students reportedly valued interdisciplinary group work ( $88 \%$ agreement; $n=45)$, real world problem-solving tasks $(88 \%)$, developing team-working skills $(86 \%)$, and reflection tasks (73\%). Quantitative data further indicated the perceived importance of mutual respect and trust for effective interdisciplinary group learning (92\%). Additionally, approximately half of responses (54\%) agreed that learning alongside students from diverse disciplines is the best way to develop their communication skills. In contrast, peer led learning did not seem to be perceived as important as other pedagogies, with just 30\% of respondents agreeing they learn more about other disciplines from their peers than from their educators. Students' perceptions were seemingly uniform across STEMM, non-STEMM and mixed incoming degree backgrounds, except in survey items on the value of teamwork (see Section 3.4).

Table 4. Students' quantitative responses on common pedagogy of interdisciplinary sustainability education. Table displays the mean and standard error (SE) of Likert scale values, the percentage of agree or strongly agree responses in parentheses, one-way ANOVA $p$ value comparing broad disciplinary subgroups and the total number of responses $(\mathrm{N})$ for each survey statement.

\begin{tabular}{cccc}
\hline Survey Statement & $\begin{array}{c}\text { Mean } \pm \text { SE 1-5 Likert } \\
\text { Scale (\% Agree or } \\
\text { Strongly Agree) }\end{array}$ & $\begin{array}{c}\text { Disciplinary } \\
\text { ANOVA } p \text { Value }\end{array}$ & N \\
\hline $\begin{array}{c}\text { For interdisciplinary group learning to work, students need to } \\
\text { respect and trust each other }\end{array}$ & $4.35 \pm 0.16(92)$ & 0.41 & 51 \\
$\begin{array}{c}\text { Working in groups with students from other disciplines is } \\
\text { valuable }\end{array}$ & $4.29 \pm 0.16(88)$ & $0.04 *$ & 51 \\
$\begin{array}{c}\text { Working on 'real world' sustainability issues helps me draw } \\
\text { connections between disciplines }\end{array}$ & $4.33 \pm 0.14(88)$ & 0.23 & 51 \\
$\begin{array}{c}\text { Interdisciplinary team-working skills are important for all } \\
\text { sustainability students to learn }\end{array}$ & $4.26 \pm 0.17(86)$ & $0.02 *$ & 37 \\
$\begin{array}{c}\text { Reflection tasks help me deepen my interdisciplinary learning } \\
\text { Communication skills are best learned with students from } \\
\text { other disciplines }\end{array}$ & $3.84 \pm 0.20(73)$ & $3.58 \pm 0.17(54)$ & 0.49 \\
$\begin{array}{c}\text { I learn about other disciplines better from other students than } \\
\text { from interdisciplinary educators }\end{array}$ & $3.14 \pm 0.21(30)$ & 0.18 & 37 \\
\hline
\end{tabular}

Notes: Likert scales were quantified as follows: strongly agree (5), agree (4), neither agree nor disagree (3), disagree (2) and strongly disagree (1). * Indicates significant difference.

\subsection{Perceived Challenges of Interdisciplinary Sustainability Education}

Within this case study, the perceived challenges of interdisciplinary training were as apparent to students as the benefits. In total, $85 \%(n=52)$ of respondents agreed that interdisciplinary education presented potential challenges. Students' 131 qualitative responses to open survey items on challenges revealed general themes related to confusion during learning, as well as the benefits of these challenges (Table 5). These responses appeared similar across students from different disciplinary backgrounds. 
Table 5. Thematic analysis of students' qualitative responses to survey items on the challenges of interdisciplinary education. General themes and their associated specific themes are presented.

\begin{tabular}{cc}
\hline General Themes & Specific Themes \\
\hline Language barriers & $\begin{array}{c}\text { Disciplinary jargon and lexicons } \\
\text { English language }\end{array}$ \\
\hline Knowledge barriers & $\begin{array}{c}\text { Assumption of incoming prior knowledge } \\
\text { Rapidly learning new disciplinary knowledge, values and conventions }\end{array}$ \\
\hline Other barriers & $\begin{array}{c}\text { Adapting to new marking and assessment styles } \\
\text { Reconciling clashes of diverse perspectives }\end{array}$ \\
\hline Benefits of these challenges & Career relevance \\
\hline
\end{tabular}

The first perceived challenge was linked to language barriers and the confusion involved with learning a range of disciplinary jargons and lexicons ( $17 \%$ of responses to items on challenges; $n=22)$. Representative responses included:

I think the biggest challenge of interdisciplinary education is breaking down barriers including communication and the ways in which each discipline approaches problem solving or aspects such as research. —non-STEMM, woman, second year, Environmental Security

Each discipline has their own jargon. It can be difficult to understand each other if we don't break things down and explain them properly, especially when there are conflicts. - Mixed prior degree, woman, second year, Leadership for Sustainable Development

English language barriers were also cited as a potential challenge for some students in a handful of responses (1\%). One student noted:

The [MES] course requires [an] excellent level of English for both speaking and writing to understand some of the concepts and requirements. I have observed that this is difficult for some students and impairs their ability to undertake the course but also their ability to be effective in group work. —non-STEMM, woman, first year, Leadership for Sustainable Development

The other main perceived obstacle was related to the differences in students' level of relevant incoming knowledge. This challenge was reportedly associated with confusion and difficulty in rapidly learning new domain areas and associated values, methods and approaches (14\%). Illustrative responses included:

Sometimes some assignments require specialized knowledge. Or some courses even require specialized knowledge on a certain topic. People may feel discouraged then. - STEMM, man, first year, Environmental Security

It's a sudden jump in the things which one has never thought/learnt before. It sometimes becomes difficult to understand. —non-STEMM, woman, first year, Environmental Security

Sometimes [interdisciplinary education] is very confusing, as everyone has a different background and a different understanding of environmental issues. - STEMM, woman, second year, Environmental Security

Less common themes included difficulty in approaching different marking and assessment conventions between units and disciplinary cultures $(1 \%)$. Representative comments included:

Depending on which interdisciplinary [units] you choose, there may be big differences in how coursework is marked ... which may become confusing. - non-STEMM, woman, commencing student, Corporate Environmental and Sustainability Management 
Speakers and educators from different disciplines do clash in their opinions that sometimes leak into their teaching and marking attitudes. - Mixed prior degree, man, second year, Leadership for Sustainable Development

A small proportion of these responses also highlighted potential difficulties in trying to reconcile clashes of perspectives with others (1\%). Illustrative statements included:

Issues can occur when the difference in perspective or beliefs [between students or educators] are significant enough to create dissonance. - non-STEMM, man, second year, Environment and Governance

Sometimes [it] is difficult to engage and communicate with people with another kind of thinking. -STEMM, woman, second year, Environmental Security

Therefore, confusion with upskilling and cultural differences between disciplines in terminology, assessment and pedagogy were perceived challenges for students within this case study. The findings on upskilling were supported by the quantitative data, although the disciplinary cultural issues or differences in perspectives were not as clear (Table 6). Approximately $26 \%$ of responses $(n=10)$ agreed that interdisciplinary curricula assume too much relevant prior knowledge and may seem confusing to students (21\%). An additional insight was that $13 \%$ of students felt that educators did not clearly synthesize disciplinary knowledge and ideas to assist with this confusion. Other less cited challenges included the potential for coursework to seem uninteresting (5\%), unnecessary (5\%), less effective than monodisciplinary education for learning problem solving skills $(5 \%)$, and a waste of time (4\%).

Table 6. Students' quantitative responses on the challenges of interdisciplinary sustainability education. Table displays the mean and standard error (SE) of Likert scale values, the percentage of agree or strongly agree responses in parentheses, one-way ANOVA $p$ value comparing broad disciplinary subgroups and the total number of responses $(\mathrm{N})$ for each survey statement.

\begin{tabular}{cccc}
\hline Survey Statement & $\begin{array}{c}\text { Mean } \pm \text { SE 1-5 Likert } \\
\text { Scale (\% Agree or } \\
\text { Strongly Agree) }\end{array}$ & $\begin{array}{c}\text { Disciplinary } \\
\text { ANOVA } \boldsymbol{p} \\
\text { Value }\end{array}$ & N \\
\hline $\begin{array}{c}\text { Interdisciplinary education assumes too much prior } \\
\text { knowledge }\end{array}$ & $2.55 \pm 0.18(26)$ & 0.60 & 39 \\
$\begin{array}{c}\text { I find interdisciplinary coursework confusing } \\
\text { Interdisciplinary educators don't make clear connections } \\
\text { between different disciplinary knowledge }\end{array}$ & $2.54 \pm 0.17(21)$ & 0.48 & 38 \\
$\begin{array}{c}\text { It is not necessary for sustainability students to engage in } \\
\text { interdisciplinary education }\end{array}$ & $1.95 \pm 0.19(13)$ & 0.73 & 38 \\
$\quad \begin{array}{c}\text { I find interdisciplinary coursework uninteresting } \\
\text { Sustainability problem solving skills are best learned within } \\
\text { my own discipline }\end{array}$ & $1.47 \pm 0.11(5)$ & 0.52 & 55 \\
$\begin{array}{c}\text { I don't want to waste my time learning interdisciplinary } \\
\text { coursework }\end{array}$ & $1.71 \pm 0.12(5)$ & 0.61 & 38 \\
I find interdisciplinary coursework irrelevant & $1.48 \pm 0.10(4)$ & 0.69 & 55 \\
\hline
\end{tabular}

Notes: Likert scales were quantified as follows: strongly agree (5), agree (4), neither agree nor disagree (3), disagree (2) and strongly disagree (1).

Encouragingly, many (44\%) students, across STEMM, non-STEMM and mixed prior degree backgrounds in this case study, responded positively to open survey items on the challenges of interdisciplinary education. Respondents typically expressed that any obstacles were, in fact, rewarding, necessary and valuable in emulating authentic professional environments in sustainability, and less to do with the education design itself. Typical insights included:

Sometimes [I find interdisciplinary coursework confusing] but I don't think that it's necessarily a bad thing. It's challenging but rewarding. - non-STEMM, woman, second year, Environmental Security 
You will inevitably have to interact and live within other domains than your specific study field, you shouldn't limit yourself. - STEMM, man, commencing student, Corporate Environmental and Sustainability Management

It is precious to work with interdisciplinary cohorts to prepare one to work well in the workforce, especially one who wishes to lead/manage organizations. -STEMM, man, first year, Environmental Security

It can be confusing but learning to ask questions in class and in forums is part of the learning ... You have to be willing to be challenged and to want to do it. Otherwise another course may suit others. - Mixed prior degree, woman, first year, Leadership for Sustainable Development

\subsection{Few Significant Differences between Disciplinary Subgroups}

Students entered the MES from a range of disciplinary backgrounds across STEMM (46\%); non-STEMM (43\%); mixed incoming degrees (including double degrees), which covered both STEMM and non-STEMM fields (11\%). Specifically, students' previous degrees included physical sciences $(36 \%)$, engineering $(22 \%)$, social sciences $(22 \%)$, marketing and/or communications $(10 \%)$, business and/or economics (9\%), international development $(7 \%)$, fashion (3\%), law (3\%), education (3\%), and others $(1 \%)$.

Overall, students' perceptions of interdisciplinary education did not seem to vary significantly with gender or broad disciplinary background (i.e., STEMM, non-STEMM and mixed prior degrees). It is important to note, however, that differences may have emerged with a larger sample. The only exception in the present case study was pedagogical approaches, specifically disciplinary subgroups' teamwork preferences. Table 7 shows that significant differences were observed in mean subgroup responses to two Likert scale statements, namely "Working in groups with students from other disciplines is valuable" (mixed prior degrees $\mathrm{m}=5.00 ; n=7$, non-STEMM $\mathrm{m}=4.47 ; n=19$ and STEMM $\mathrm{m}=3.88 ; n=25$ ) and "Interdisciplinary team-working skills are important for all sustainability students to learn" (mixed prior degrees $\mathrm{m}=5.00 ; n=7$, non-STEMM $\mathrm{m}=4.53 ; n=19$ and STEMM $\mathrm{m}=3.80 ; n=25$ ).

Table 7. One-way ANOVA analysis comparing broad disciplinary subgroups' responses to the following survey statements.

\begin{tabular}{cccccc}
\hline Survey Statement & & $\begin{array}{c}\text { Sum of } \\
\text { Squares }\end{array}$ & Df & $\begin{array}{c}\text { Mean } \\
\text { Square }\end{array}$ & F \\
\hline Working in groups with & Between groups & 8.31 & 2.00 & 4.15 & 3.48 \\
students from other disciplines & Within groups & 57.38 & 48.00 & 1.20 & 0.04 \\
is valuable & Total & 65.69 & 50.00 & & \\
\hline Interdisciplinary team-working & Between groups & 10.44 & 2.00 & 5.22 & 4.27 \\
skills are important for all & Within groups & 58.74 & 48.00 & 1.22 & 0.02 \\
sustainability students to learn & Total & 69.18 & 50.00 & & \\
\hline
\end{tabular}

Bonferroni post hoc analyses indicated that students from mixed prior degrees agreed significantly more to both aforementioned statements than those from non-STEMM and STEMM groups. Considering the small proportion of respondents to these survey items from mixed prior degrees (i.e., seven students), this variance only suggests a trend and needs to be treated with caution. Additionally, students from non-STEMM backgrounds showed some possible evidence of agreeing somewhat more to both statements than those from STEMM backgrounds, though this difference was not statistically significant. Larger and more equal sample sizes would have increased the confidence and rigor in the interpretation of any significant or non-significant differences. Statistical datasets are available in the Supplementary Materials. Figures 1 and 2 display boxplots of the spread of these responses per disciplinary subgroup. 


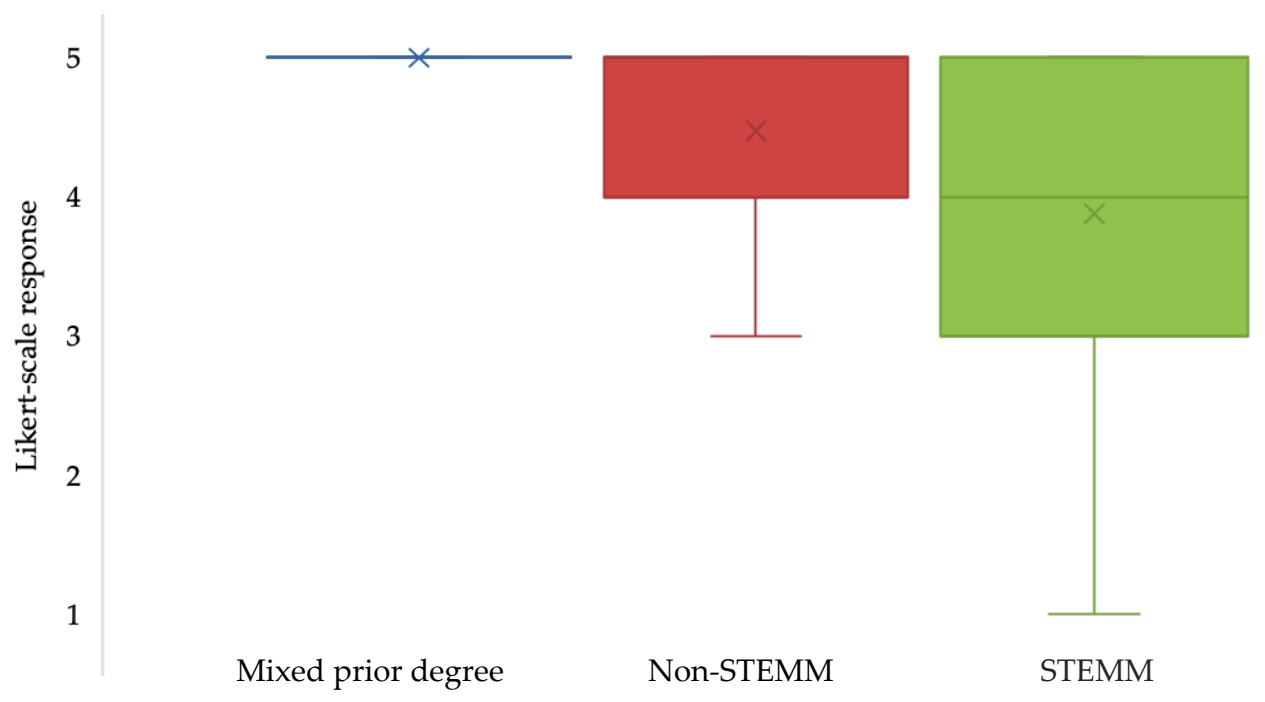

Figure 1. Boxplot displaying disciplinary differences in quantitative responses to the survey statement "Working in groups with students from other disciplines is valuable." Likert scale statements were quantified as follows: strongly agree (5), agree (4), neither agree nor disagree (3), disagree (2) and strongly disagree (1). Boxplot shows the spread of values for students from mixed prior degrees $(\mathrm{m}=5.00 ; n=7)$, non-STEMM $(\mathrm{m}=4.47 ; n=19)$ and STEMM $(\mathrm{m}=3.88 ; n=25)$ backgrounds.
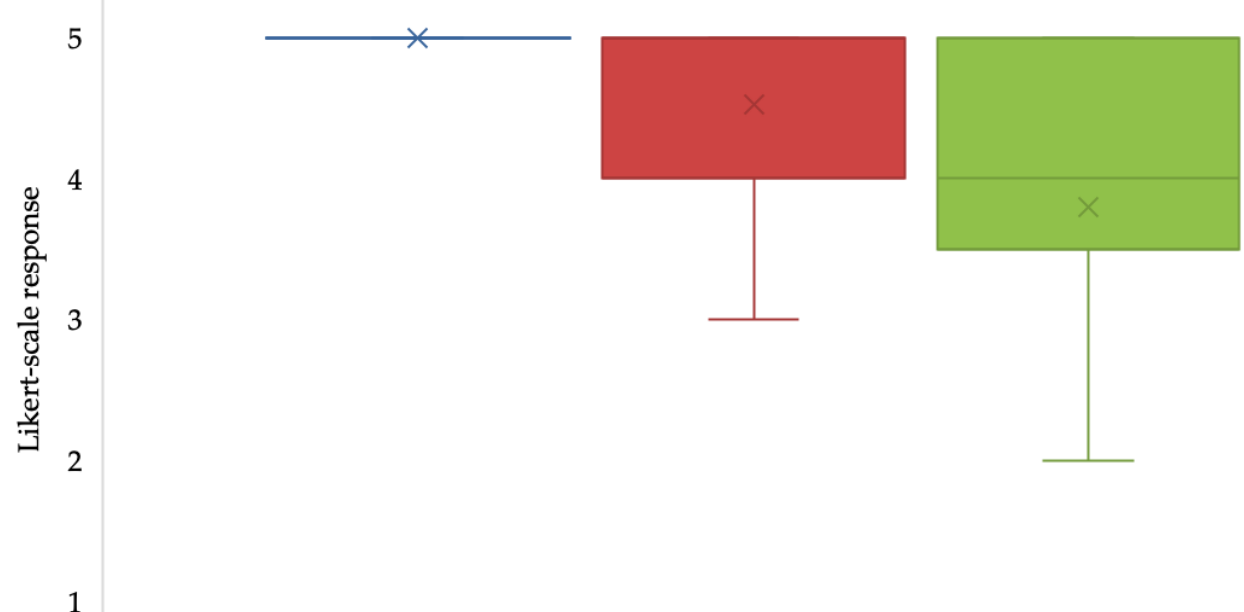

Mixed prior degree

Non-STEMM

STEMM

Figure 2. Boxplot displaying disciplinary differences in quantitative responses to the survey statement "Interdisciplinary team-working skills are important for all sustainability students to learn." Likert scale statements were quantified as follows: strongly agree (5), agree (4), neither agree nor disagree (3), disagree (2) and strongly disagree (1). Boxplot shows the spread of values for students from mixed prior degrees $(\mathrm{m}=5.00 ; n=7)$, non-STEMM $(\mathrm{m}=4.53 ; n=19)$ and STEMM $(\mathrm{m}=3.80 ; n=25)$ backgrounds.

Interestingly, these results contrast with findings of an aforementioned related survey item "Interdisciplinary education helps me become a better team worker" in Section 3.1, where there were no significant differences observed between broad disciplinary subgroups ( $p=0.62$; Table 2$)$. Taken together, these possible trends in disciplinary differences in students' views on interdisciplinary teamwork related to perceived value rather than perceived team-working abilities. 


\section{Discussion}

This case study explored the question of "how do postgraduate students perceive highly integrated interdisciplinary coursework?" The results, discussed below, highlight that students from diverse backgrounds within the MES perceived interdisciplinary training positively and relatively similarly, at least based upon the sample. Our four sub-questions further explored the reasons why students valued the coursework, why they might have perceived it to be challenging and which pedagogical approaches they preferred. We also sought to understand whether students from different disciplinary backgrounds experienced and perceived the coursework differently. In doing so, we aimed to provide a preliminary insight into how interdisciplinary educators might optimize learning experiences for students similar to learners in this case study, with potential broader value to other programs. In short, the dominant benefits perceived by students were career relevance, cognitive benefits and confidence in envisioning sustainability solutions. These benefits were typically perceived to last into students' professional lives and foster lifelong learning ahead. In terms of interdisciplinary pedagogy, students perceived this as valuable, if somewhat challenging. Students in this case study viewed the pedagogies featured in interdisciplinary coursework as authentic to the work environment, which offers a relatively novel finding to this research field. Students' main perceived challenges were generally language and knowledge barriers, as is expected in diverse cohorts and reflected in past studies. In terms of whether there were differences in students' perceptions between broad incoming disciplinary backgrounds, we found very little preliminary evidence. We did observe, however, some possible distinction in terms of value of teamwork activities. Our results show a picture of students' perceptions within a case study and must be treated with caution due to the sample size and self-selected cohort. In saying that, our case study does support some findings of a small but growing body of research on students' perceptions across other courses and disciplinary domains.

In the following sections, we first provide context for the discussion. We then explore each of the research sub-questions, beginning with the possible differences between disciplinary subgroup perceptions, moving through to the perceived benefits of interdisciplinary coursework, then perceptions of common pedagogy and on to students' perceived challenges. The discussion concludes by detailing the limitations and implications of this case study.

\subsection{Context for the Discussion}

Higher education programs in sustainability are becoming more prevalent and more interdisciplinary. Friedow [2] cites a 2009 report showing over half of the 400 American Association of Colleges and University member institutions surveyed were undergoing reform to include more interdisciplinary curricula. In 2016, Millar [3], too, stated that "[Australian] universities are increasingly offering interdisciplinary subjects and programmes as an alternative to or alongside disciplinary subjects" (p. 471). Sustainability degrees are also increasingly incorporating additional disciplinary areas, such as business, finance, policy and law. Furthermore, these degrees are accepting much more diverse student cohorts in terms of disciplinary background, especially at the postgraduate level. Previous research of such highly integrated programs has often focused on educators' perspectives, course design or institutional barriers. While those elements are important, less focus has been given to exploring students' perceptions and learning experiences. Considering the dearth of literature on students' perspectives, we were interested in how students from different backgrounds experienced and perceived interdisciplinary training. Specifically, what are the perceived educational challenges, benefits and preferred pedagogical approaches of a diverse student cohort enrolled in a highly integrated sustainability degree? Is interdisciplinary instruction accessible to students from a range of incoming disciplinary backgrounds, and why? This case study thereby acknowledges the importance of students' voices in deepening our understanding of how complex interdisciplinary instruction is perceived and provides students a platform to participate in this discourse.

Students' views in the present program on interdisciplinary education largely aligned with previous studies reporting cognitive benefits, such as expanded worldviews, cross-sector knowledge 
and critical thinking. In the current case study, however, we identified a stronger emphasis from students on skills and awareness relevant to sustainability careers and finding solutions to sustainability problems. Students' main perceived challenges were also largely typical of previous studies and involved confusion with rapidly learning new disciplines and disciplinary lexicons. Other reported obstacles were the assumption of some level of relevant incoming knowledge and disciplinary clashes in perspectives. This case study importantly shows, however, that these challenges were not necessarily considered insurmountable by students in the sample. Rather, the challenges were perceived as an authentic reflection of the realities of their future professional practice. In brief, students from diverse disciplinary backgrounds reported similar educational benefits, challenges and pedagogical preferences, with the possible exception of valuing teamwork. Overall, diverse students within the MES perceived highly interdisciplinary coursework to be valuable, accessible and relevant to their future careers in sustainability. These findings may also be meaningful for similar highly interdisciplinary degrees and training in other fields.

\subsection{Disciplinary Background Did Not Appear to Substantially Affect Students' Perceptions of Interdisciplinary Education}

Students from a vast variety of disciplinary backgrounds in this case study reported similar perceived challenges and benefits of highly interdisciplinary coursework, as well as pedagogical preferences. These findings indicate that it is perhaps not necessary to tailor coursework to students' incoming disciplines, as suggested by Warburton [33], who suspected that science students may require specific support to assist their holistic and critical thinking for interdisciplinary learning more than others. On the other hand, Feng [11] found that science students favored a highly interdisciplinary sustainability program with units on "geography, chemistry, history, media, economics, administration, engineering and architecture" (p. 38) more than humanities students. Scientific concepts and worldviews felt somewhat inaccessible and unrelatable to humanities students in that study. Those findings, however, were not observed in the present case study in the sense that STEMM and non-STEMM students seemed to report similar views, noting our sample size limited statistical power. In our case study, students from both STEMM and non-STEMM articulated similar obstacles and collectively expressed that their desire to bridge disciplines enabled them to navigate and embrace these challenges.

In general, the results of this case study align with other limited previous research, suggesting that interdisciplinary curricula may be effective and appropriate for highly diverse learners spanning STEMM and non-STEMM [24,32]. Burns [24] explored a similar highly interdisciplinary program, diverse cohort and pedagogical approach to that of the present study. The program featured topics on "food systems, alternative technology, financing, immigration, and resource management" (p. 168). The author found that the program was effective for students' interdisciplinary learning across different year levels, disciplinary backgrounds and majors. Burns [24] further supported our findings that pedagogical tools, such as reflection tasks, presenting multiple perspectives, and participatory and experiential learning were generally effective for diverse student groups. Likewise, Noy et al. [32] reported that similar generalized pedagogies were suitable for a broad range of students in an undergraduate program blending "health, agriculture, research, business, property and environmental advocacy" (p. 101). The authors found that group work, challenging students' worldviews, peer led learning and reflection tasks helped students from a range of disciplinary backgrounds to feel more competent and confident in their future sustainability careers. The present case study supports this small but growing body of literature on the perceptions, experiences and accessibility of highly interdisciplinary training in sustainability. This body of studies is important due to the likely rise of these programs in global higher education [3].

Since the aforementioned diverse cohorts of students shared common perceptions as the present case study [24,32], highly interdisciplinary coursework appears to carry the benefits of a more nuanced examination of sustainability issues without alienating disciplinary subgroups of students (at least 
within a self-selected sample). The general pedagogical approaches featured in the present case study appeared valuable and accessible to students from a range of backgrounds, including STEMM and non-STEMM. These findings suggest that as interdisciplinary programs integrate more disciplines and welcome more diverse cohorts, generalized interdisciplinary coursework appears suitable from the student perspective. Further studies focusing on different programs in sustainability and other fields are still required. Our findings, however, when taken in concert with the aforementioned literature, offer preliminary evidence to support interdisciplinary educators across a range of fields to incorporate more domains in their programs. Similarly, these courses appear appropriate for a broad range of students from STEMM and non-STEMM when paired with established and common interdisciplinary pedagogies.

It is important to recognize that the seeming accessibility of these highly integrated degrees and pedagogical approaches in the present study could also be an effect of using a self-selected cohort, which is common in case studies. Namely, relative to the wider student population, students enrolled in the MES course may carry more positive expectations of the program, see value in interdisciplinary education and believe in their own abilities to perform well, in line with Eccles' expectancy-value theory [53]. Using self-selected cohorts is nevertheless beneficial for exploring authentic students' perceptions and informing course design for future students who enroll in such programs. To tease out any potential effect of this case-based sampling method, future studies could build on our preliminary findings by surveying perceptions of interdisciplinary education on non-self-selected cohorts. Future research could also include multiple interdisciplinary programs with highly diverse cohorts to understand the transferability of our results to a wider range of students who explicitly choose these programs.

While there were no major differences in responses between STEMM and non-STEMM subgroups in the present case study, we observed a small statistical difference in relation to the value of teamwork as a pedagogical tool. Specifically, there was a possible trend for students from mixed prior degrees and non-STEMM backgrounds towards valuing interdisciplinary teamwork more than those from STEMM. The broader literature offers some evidence that interdisciplinary collaboration and teamwork activities may polarize students in this way [54-57]. In terms of double versus single incoming degrees, Williams et al. [56] found that health professions students undertaking double degrees produced higher mean scores on teamwork and collaboration items of the RIPLS survey (which our survey instrument was based upon) than those from single degrees. Regarding the influence of disciplinary backgrounds, studies have found that highly specialized and siloed medical students seem more averse to interdisciplinary teamwork and collaboration than those from nutrition and nursing [54,57]. These findings suggest that students' perceptions of relevance and or exposure to interdisciplinarity may influence perceived value. Relating this to our findings, perhaps students from mixed/double degrees valued interdisciplinary collaboration more highly as a result of prior exposure to two styles of education. Further, STEMM students may have potentially felt that team-working skills were less important than other learning outcomes typically valued in their home disciplines, such as individual knowledge acquisition [58]. In which case, disciplinary factors such as faculty culture, preferred pedagogy, "academic elitism" and/or a strongly siloed approach in students' prior degrees may potentially be at play [59]. Other factors may also impact the perceived value of teamwork. For example, while we did not assess the influence of professional experience on students' views, educators have informally reported that students with professional sustainability experience perceive higher teamwork value due to greater awareness of work-relevance. Thus, factors such as previous experience in teamwork, a focus on knowledge sharing, extent of specialization and common learning activities in prior degrees may have influenced students' value of interdisciplinary collaboration and teamwork. Encouragingly, though, our case study suggests that, in general, previous learning is not a major factor in perceptions of common interdisciplinary pedagogy. Further research with a larger sample is, however, needed to clarify any possible disciplinary influences on students' perceptions of teamwork and how this may impact interdisciplinary learning and course design more generally. 
To summarize, the findings of this case study, when considered in concert with others, suggest that interdisciplinary instruction is perceived as accessible to students from a suite of incoming disciplinary backgrounds across STEMM and non-STEMM. As such, students who choose this type of training may be able to readily learn and carry sustainability principles into industries as diverse as fashion through to engineering.

\subsection{Students Cited Career Relevance, Expanded Knowledge and Perspectives, and Confidence in Envisioning Sustainability Solutions as Major Benefits}

This case study found that the reported overarching benefits of interdisciplinary education were perceptions of: (1) career relevance, including development of cross-sector communication and collaborative skills; (2) cognitive benefits such as critical thinking and nuanced worldviews; (3) confidence in envisioning new and creative solutions to global issues more than perhaps would have been possible in traditional monodisciplinary contexts.

In terms of professional development, this study unearthed a strong focus by students on preparation for their future careers as well as readying themselves to drive solutions to the big issues of our time. This may be a reflection of the current climate whereby younger people are expressing great concern for environment and sustainability issues through youth activism and dissent [60]. A recent Deloitte Global [61] report suggested that environment and sustainability were the major concerns for millennials and generation Zs, with careers and job security a second major concern. Given this dual focus, it is perhaps understandable that careers and solutions to sustainability issues were common themes in this case study. Students perceived the development of employability skills and interprofessional relationships in terms of their aptitude for communication, stakeholder engagement, interprofessional networking and confidence to work in pluralistic sustainability careers. Thus, becoming a boundary-spanner or T-shaped professional, with breadth and transferability plus depth and expertise [62], appeared important to students in this sample to succeed as a sustainability practitioner.

The broader literature in both interdisciplinary environmental [63] and health professions [64] education supports our findings that students see career benefits from learning in heterogenous classrooms. Namely, students perceived the improvement of communication skills and opportunities to build interprofessional relationships. To illustrate, Moslemi et al. [63] found that interdisciplinary education gave postgraduate science students valuable opportunities to collaborate and communicate with peers in other departments. Likewise, Michalec et al. [64] found that health professions students enjoyed socializing and working with peers in other disciplines, importantly seeing professional gain. Taken together, cross-sector learning environments seem to offer students opportunities to refine their communication skills, build self-confidence, deepen their understanding and appreciation of other professions, and network with future professionals in related fields. All of these attributes represent the industry-relevant competencies that employers look for in modern graduates [21] and speak to the benefits of disciplinarily diverse cohorts. These findings collectively suggest that a range of student backgrounds within a cohort is not necessarily an issue, although it can require patience and navigating clashes in perspectives, echoed in the present and existing studies [11,32,65].

Interestingly, these findings mirror those from some studies of short, dedicated careers workshops. For instance, Sarkar et al. [22] found that undergraduate students valued careers workshops for similarly providing professional networking opportunities. Interdisciplinary training could, therefore, provide comparable networking opportunities to extracurricular careers workshops that often cost time and resources to attend. In fact, learning in diverse classrooms for the length of a degree, such as the MES, arguably provides students even more opportunities than add-on careers workshops for authentic cross-sector relationship building necessary for the UN SDG 17: Partnerships for the Goals [42]. These employability and networking opportunities may be one reason that students of the present case study felt that the benefits of interdisciplinary instruction would persist into their professional lives. 
Engaging with novel disciplinary knowledge and perspectives within the program in the present case study was also viewed by students as providing cognitive benefits useful for finding sustainability solutions. Specifically, students reported that their problem-solving and critical thinking skills could be boosted by prompts to examine the advantages and limitations of students' home disciplines, find connections between various domains and reflect on their learning journeys. Our findings here align with other studies on students' perceptions. Melding a high variety of knowledge domains and perspectives in education has been found to increase students' perceived appreciation and critical understanding of the interrelated nature of sustainability issues $[19,24,32,66]$. For example, a study by Eastwood et al. [66] showed that students gained quantifiable cognitive benefits from undertaking an interdisciplinary undergraduate major (covering topics on environment, ecology, human health and disease). The authors studied students on various career paths and backgrounds across healthcare, business, psychology and law. Interdisciplinary students showed more sophisticated levels of reasoning with socio-scientific issues and tended to incorporate more varied perspectives into their decision making than monodisciplinary biology students. Thus, interdisciplinary training appears to encourage the development of cognitive skills, such as critical and systems thinking more than traditional monodisciplinary programs. These outcomes could arguably be further pronounced in more highly integrated degrees, such as the MES, given the breadth of topics learned. Students' of the present case study, across STEMM, non-STEMM and mixed prior degree backgrounds, appeared to recognize these benefits and directly compared them to their previous monodisciplinary degrees. These insights were encapsulated in the following responses:

I more or less had only one way of thinking about the environment because my undergrad was very specific to a field of study but now my perspective has broadened. -STEMM, woman, first year, International Development and Environment

Learning through other disciplines has made me appreciate aspects that I may never have had the ability to experience in a single discipline. -non-STEMM, woman, second year, Environmental Security

Normally with a specific background we tend to think only one-way but surrounded with different background you open your mind. -STEMM, woman, second year, Environmental Security

4.4. Students Valued Pedagogical Approaches Focused on Cross-Sector Communication, Critical Thinking and Real World Simulations

The benefits of interdisciplinary education seem to come from certain pedagogical tools, which educators working in sustainability and a range of other fields may take advantage of. Students in the present case study reportedly valued experiential learning through real world problem- and project-based tasks. Examples of these experiential tasks include drafting policy documents and examining case studies [33], field visits [24], consultancy projects with industry and government, and internships [27]. Experiential learning tasks are thought to aid critical thinking and confidence in problem solving [28], both of which students in the present case study mentioned as benefits of interdisciplinary education. Additionally, students tended to report that educator led learning was more effective than peer led learning for their cross-disciplinary knowledge acquisition, in alignment with a recent meta-analysis [67]. Students in the present case study, instead, appeared to value peer interactions and collaboration more for refining their cross-sector communication and engagement skills (previously explored in Section 4.3). Reflection tasks were another pedagogic tool that the present cohort valued for further developing their critical thinking and integrating their interdisciplinary learning. (Noting that a handful of responses mentioned that assessed reflections may feel somewhat contrived or ineffective.) These benefits of reflection tasks are well documented in the broader literature, especially the opportunities afforded for students to contemplate their learning journey [19], assess knowledge claims [68], challenge assumptions and develop thoughtful arguments [69]. Students 
cited such benefits in the present study often in relation to authentic professional practice and career applicability. As such, the present case study supports the value of these common pedagogical tools to impart interdisciplinary learning and boost students' confidence to work in sustainability professions.

\subsection{Students' Main Perceived Challenges Were Language and Knowledge Barriers, While Noting Career Relevance}

Unsurprisingly, as with any other educational program and learning experience, students within the MES perceived some learning challenges. Some respondents in this case study reported that interdisciplinary coursework may be confusing at times and there was an assumption of a certain level of incoming relevant knowledge. These findings are supported in the literature regarding interdisciplinary pedagogy $[11,70]$. Such confusion and disorientation are, however, not necessarily downfalls of interdisciplinary education per se. Instead this phenomenon represents a well-documented natural state arising from operating between traditional lines of thought [2], challenging one's own worldviews and assumptions [71], and re-evaluating one's academic identity [72] in interdisciplinary learning contexts. Scholars also suspect that confusion may come about during thematic [24] and experiential learning [73]. This confusion may occur when students are required to undertake their own independent synthesis of knowledge across novel domains or use skills and knowledge they may not have acquired yet [70]. This difficulty may specifically occur during problem- and project-based learning tasks that simulate the complexity of authentic conundrums without simple textbook answers [73]. Friedow [2] explored how the discomfort and uncertainty associated with such learning approaches may be a beneficial pathway to learning, if well contextualized and explained as a learning approach. These potential obstacles during interdisciplinary learning may also arise from educators' use of discipline-specific jargon and lexicons, especially when the language of instruction is a foreign language for the student [11]. Students with non-cognate and linguistically diverse backgrounds may therefore be disadvantaged in interdisciplinary programs if educators do not account for these challenges. To address these potential issues, educators could use scaffolding [74] — for example, by embedding research workshops into curricula to help students locate new information. Offering well clarified assignment templates and plain language rubrics could also help introduce students to novel disciplinary conventions and expectations [75]. Explicitly conveying the value of discomfort and uncertainty around learning to navigate and integrate disciplines may also be valuable. There is some evidence, however, from the present case study to suggest that self-selected students may already appreciate this.

Indeed, this case study found that students, at least from our sample, do recognize the benefits and authenticity of the challenges that interdisciplinary education presents. Our preliminary findings suggest that such diverse student groups perceive the aforementioned challenges as mirroring the authentic difficulties of becoming a boundary spanning sustainability professional. Indeed, this sample of students recognized the context of the complex nature of sustainability issues and the professional challenges of developing cross-sector partnerships for achieving the SDGs [42]. Employment opportunities in sustainability will inevitably present graduates with uncertainties, a diverse network of stakeholders, sector specific communication styles and information to grapple with [76]. One respondent in the present study elegantly captured this, summarizing the benefits of learning to find innovative solutions and engage in cross-sector collaboration:

Working with different people and learning from them [will enable] me to think that problems require different ideas to get solved. This, in future careers could be a beneficial pathway to already have an experience in dealing and working with a range of stakeholders. -STEMM, man, second year, Environment and Governance

In summary, in line with a small but growing body of literature, students of the present case study reportedly valued interdisciplinary coursework for expanding their knowledge, worldviews and cognitive skills (i.e., problem solving, decision-making, critical thinking, lifelong learning and holistic perspectives), as well as for career readiness (i.e., communication, team-working and collaboration). 
These benefits seemed to build students' confidence in envisioning and working towards authentic complex sustainability solutions. Indeed, this desire for professional breadth and depth, and skill in approaching complexity, is said to be generally lacking in modern graduates and highly desirable to employers [21]. Further studies of other cohorts are required to understand the transferability of our findings to other types of training and student groups, and to explore mechanisms or causes behind students' perceptions. Our preliminary findings do, however, mirror a limited number of similar past studies while also introducing ideas around authentic learning contexts and career impact. These elements are worth exploring further in future studies since graduates will be confronted with a complexity of professional roles, interactions and information in sustainability and leadership. Interdisciplinary learning is additionally seen by the UN as an important foundation for students' careers $[23,42]$. The present case study suggests that students also recognized this and reportedly value the challenge of learning new fields and upskilling rapidly through them. Our preliminary findings may encourage course designers from a range of fields to present students with more diverse disciplinary knowledge and perspectives as well as career-related framing of this type of learning. In doing so, educators could help deepen students' engagement with and appreciation of the challenges of interdisciplinarity while benefiting students' relevant employability and cognitive skills. These findings may additionally support interdisciplinary educators generally to dedicate space and time for cross-disciplinary peer interactions to foster budding relationships, both professional and academic.

\subsection{Limitations}

Like many previous case studies, the present case study was subject to limitations. Firstly, the sample population was relatively small (61 students) and a self-selected cohort who had enrolled in the MES program. While this study did focus on one cohort, some of the findings are supported by previous studies of other courses, suggesting their possible transferability. Additionally, comparable self-selected cohort sizes also feature in similar studies within health professions education [77-79] and sustainability education [32]. Attrition in response rates along the survey and the sample size also meant we were only able to preliminarily indicate possible trends in the perceptions of students from different disciplinary backgrounds. Larger studies are needed to investigate these possible trends further. Furthermore, the scope of this case study did not include a comparison of other potentially influential demographic factors, such as age, specialization or stream, professional experience, cultural and linguistic backgrounds-for example, English as a foreign language and cross-cultural factors would be expected to amplify challenges of learning in an interdisciplinary setting $[80,81]$. The study response rate was also relatively low and, therefore, response and non-response biases may be present. We note, however, that gaining a general view of how all students in this particular course responded to interdisciplinary education was not the purpose of the case study. Instead, we focused on preliminarily exploring how students from diverse backgrounds within a highly interdisciplinary program perceived and experienced this type of coursework. We endeavored to assist educators to enhance programs in this rapidly growing space for students who choose this form of education. This sampling method and study design was, therefore, fit for purpose in achieving this aim.

\section{Conclusions}

The present preliminary case study explored the experiences and perceptions of a diverse postgraduate sample enrolled in a highly interdisciplinary sustainability program (MES). The MES coursework melds a wide range of disciplines including arts, science, sustainable development, business and economics, international development, governance and policy. Given that research on interdisciplinary coursework tends to focus on educators' viewpoints, this case study instead offers an insight into how diverse student cohorts perceive these new and emerging highly interdisciplinary programs. A major strength of this case study was in surveying students across a broad range of incoming disciplinary backgrounds, from fashion through to engineering. 
Almost all respondents in this case study reportedly appreciated interdisciplinary education for expanding their knowledge, skills and perspectives. Interdisciplinary coursework was valued for boosting students' confidence in building their future careers and ability to drive solutions to major sustainability issues. Further, interdisciplinary training appeared to be accessible to students from a range of incoming degrees. While students perceived some challenges associated with rapidly upskilling into new domains, students often saw these challenges as authentic to becoming a boundary spanning sustainability practitioner. The mechanisms behind students' perceptions, however, were not explicitly explored in this study and require further investigation. Although the results presented here may simply reflect the particulars of the case study, our findings were often supported by other research. We did observe, however, a stronger focus on careers and envisioning sustainability solutions in the present study than found in previous research. This case study contributes to the small but growing body of literature suggesting that such highly interdisciplinary coursework is accessible and empowering to future sustainability leaders across a wide spectrum of disciplines (i.e., STEMM and non-STEMM). Interdisciplinary educators from other fields, such as health professions, may also be encouraged to include more diverse domains and student cohorts in their programs when using similar pedagogical approaches.

Supplementary Materials: The following are available online at http:/www.mdpi.com/2071-1050/12/21/8898/ s1, Dataset of statistical tests analyzing responses from STEMM, non-STEMM and mixed prior degree student subgroups.

Author Contributions: Conceptualization, J.K.A. and S.S.Y.H.; methodology, J.K.A. and S.S.Y.H.; validation, J.K.A. and S.S.Y.H.; formal analysis, J.K.A.; investigation, J.K.A. and S.S.Y.H.; resources, S.S.Y.H.; data curation, J.K.A.; writing — original draft preparation, J.K.A. and S.S.Y.H.; writing—review and editing, J.K.A. and S.S.Y.H.; visualization, J.K.A. and S.S.Y.H.; supervision, S.S.Y.H.; project administration, J.K.A. and S.S.Y.H.; funding acquisition, N/A. All authors have read and agreed to the published version of the manuscript.

Funding: This research received no external funding.

Acknowledgments: The authors would like to thank the participants of this case study for generously sharing their insights into interdisciplinary sustainability education. We would also like to generally thank all of the Monash University students and academic staff of the Master of Environment and Sustainability.

Conflicts of Interest: Both authors are affiliated with the Master of Environment and Sustainability program that is the focus of this case study.

\section{References}

1. Klein, J.T. A Platform For a Shared Discourse of Interdisciplinary Education. J. Soc. Sci. Educ. 2006, 5, 10-18.

2. Friedow, A. Interdisciplinary Pedagogy: An Angle of Approach. Ph.D. Thesis, University of Nebraska, Lincoln, NE, USA, 2014.

3. Millar, V. Interdisciplinary Curriculum Reform in the Changing University. Teach. High. Educ. 2016, 21, 471-483. [CrossRef]

4. Olenick, M.; Allen, L.R.; Smego, R.A., Jr. Interprofessional Education: A Concept Analysis. Adv. Med. Edu. Prac. 2010, 1, 75-84. [CrossRef]

5. Svanström, M.; Lozano-García, F.J.; Rowe, D. Learning Outcomes for Sustainable Development in Higher Education. Int. J. Sustain. High. Educ. 2008, 9, 339-351. [CrossRef]

6. Aktas, C.B. Reflections on Interdisciplinary Sustainability Research with Undergraduate Students. Int. J. Sustain. High. Educ. 2015, 16, 354-366. [CrossRef]

7. World Commission on Environment and Development. Our Common Future; Oxford University Press: Oxford, UK, 1987.

8. Incropera, F.P. Climate Change: A Wicked Problem: Complexity and Uncertainty at the Intersection of Science, Economics, Politics, and Human Behavior; Cambridge University Press: New York, NY, USA, 2016.

9. D'Hainaut, L. Interdisciplinarity in General Education. In International Symposium on Interdisciplinarity in General Education; UNESCO: Paris, France, 1986.

10. Klein, J.T.; Miller, R.C. The Dialectic and Rhetoric of Disciplinary and Interdisciplinary. Issues Integr. Stud. 1983, 2, 35-74. 
11. Feng, L. Teacher and Student Responses to Interdisciplinary Aspects of Sustainability Education: What do we Really Know? Environ. Educ. Res. 2012, 18, 31-43. [CrossRef]

12. Hiller Connell, K.Y.; Remington, S.M.; Armstrong, C.M. Assessing Systems Thinking Skills in Two Undergraduate Sustainability Courses: A Comparison of Teaching Strategies. Available online: http: //hdl.handle.net/2097/13783 (accessed on 22 October 2020).

13. Moore, D.; Almeida, S.C.; Barnes, M.M. Education for Sustainability Policies: Ramifications for Practice. Aust. J. Teach. Educ. 2018, 43, 105. [CrossRef]

14. Edwards, D.B.; Sustarsic, M.; Chiba, M.; Mccormick, M.; Goo, M.; Perriton, S. Achieving and Monitoring Education for Sustainable Development and Global Citizenship: A Systematic Review of the Literature. Sustainability 2020, 12, 1383. [CrossRef]

15. Fortuin, K.; Van Koppen, C. Teaching and Learning Reflexive Skills in Inter-and Transdisciplinary Research: A Framework and its Application in Environmental Science Education. Environ. Educ. Res. 2016, 22, $697-716$. [CrossRef]

16. Dale, A.; Newman, L. Sustainable Development, Education and Literacy. Int. J. Sustain. High. Educ. 2005, 6, 351-362. [CrossRef]

17. Brogdon, R.; Rowsey, R. Some Effects of an Interdisciplinary Environmental Education Effort. J. Environ. Educ. 1977, 8, 26-31. [CrossRef]

18. Ho, S.S.; Wong, B.B.; Tham, M.; Brookes, R.H. Science Undergraduates are Motivated to Undertake Leadership Education To Enhance Employability and Impact. Int. J. Innov. Sci. Math. Educ. 2016, 24, 71-83.

19. Howlett, C.; Ferreira, J.; Blomfield, J. Teaching Sustainable Development in Higher Education: Building Critical, Reflective Thinkers Through an Interdisciplinary Approach. Int. J. Sustain. High. Educ. 2016, 17, 305-321. [CrossRef]

20. Stubbs, W.; Ho, S.S.Y.; Abbonizio, J.; Paxinos, S.; Bos, J.J. Addressing The SDGs Through an Integrated Model Of Collaborative Education. In Teaching and Sustainable Development: Using the Transformative Power of Teaching to Raise Awareness on Sustainable Development and Achieve the UN Sustainable Development Goals; Edward Elgar Publishing, Thomson Reuters: Cheltenham, UK, 2020. (In Press)

21. Jackson, D. An International Profile of Industry-Relevant Competencies and Skill Gaps in Modern Graduates. Int. J. Manag. Educ. 2010, 8, 29-58. [CrossRef]

22. Sarkar, M.; Overton, T.; Thompson, C.; Rayner, G. Graduate Employability: Views of Recent Science Graduates and Employers. Int. J. Innov. Sci. Math. Educ. 2016, 24, 31-48.

23. United Nations Environmental Programme. Green Jobs: Towards Decent Work in a Sustainable, Low-Carbon World. 2008. Available online: https://www.ilo.org/wcmsp5/groups/public/---ed_emp/--emp_ent/documents/publication/wcms_158727.pdf (accessed on 22 October 2020).

24. Burns, H. Meaningful Sustainability Learning: A Study of Sustainability Pedagogy in Two University Courses. Int. J. Teach. Learn. High. Educ. 2013, 25, 166-175.

25. Smith, B.L. The Challenge of Learning Communities as a Growing National Movement. In Proceedings of the Association of American Colleges and Universities Conference on Learning Communities, Providence, RI, USA, 3 March 2001.

26. Dede, C. Comparing Frameworks for 21st Century Skills. In 21st Century Skills: Rethinking how Students Learn; Bellanca, J., Brandt, R., Eds.; Solution Tree Press: Bloomington, IN, USA, 2010; pp. 51-76.

27. Wilson, R.F. Issues and Strategies for Establishing Work-Integrated Learning for Multidisciplinary Teams: A Focus on Degrees in Sustainability. Asia Pac. J. Coop. Educ. 2015, 16, 355-366.

28. Qing, Z.; Ni, S.; Hong, T. Developing Critical Thinking Disposition by Task-Based Learning in Chemistry Experiment Teaching. Procedia Soc. Behav. Sci. 2010, 2, 4561-4570. [CrossRef]

29. Marvell, A.; Simm, D.; Schaaf, R.; Harper, R. Students as Scholars: Evaluating Student-Led Learning and Teaching During Fieldwork. J. Geogr. High. Educ. 2013, 37, 547-566. [CrossRef]

30. Collins, S.M. Examining Interdisciplinary Education and Collaboration in Higher Education. Ph.D. Thesis, St. Catherine University, Minneapolis, MI, USA, 2017.

31. Ballantyne, R.; Anderson, D.; Packer, J. Exploring the Impact of Integrated Fieldwork, Reflective and Metacognitive Experiences on Student Environmental Learning Outcomes. Aust. J. Environ. Educ. 2010, 26, 47-64. [CrossRef] 
32. Noy, S.; Patrick, R.; Capetola, T.; Mcburnie, J. Inspiration from the Classroom: A Mixed Method Case Study of Interdisciplinary Sustainability Learning In Higher Education. Aust. J. Environ. Educ. 2017, 33, 97-118. [CrossRef]

33. Warburton, K. Deep Learning and Education for Sustainability. Int. J. Sustain. High. Educ. 2003, 4, 44-56. [CrossRef]

34. Boyer, S.J.; Bishop, P.A. Young Adolescent Voices: Students' Perceptions of Interdisciplinary Teaming. Res. Middle Level Educ. 2004, 28, 1-19. [CrossRef]

35. Annan-Diab, F.; Molinari, C. Interdisciplinarity: Practical Approach to Advancing Education for Sustainability and for the Sustainable Development Goals. Int. J. Manag. Educ. 2017, 15, 73-83. [CrossRef]

36. Burns, H. Teaching for Transformation: (Re)Designing Sustainability Courses Based on Ecological Principles. J. Sustain. Educ. 2011, 2, 1-5.

37. Mcclellan, E.D.; Johnson, A.G.; Neely, A.D.; Tanenbaum, L.; Miller, K.; Duffy, L.N.; Mowatt, R.A.; Fuchs, M.; Salisbury, M.A.; Door, V.M. Deep Interdisciplinarity as Critical Pedagogy: Teaching at the Intersections of Urban Communication and Public Place and Space. Int. J. Crit. Pedag. 2014, 5, 5-23.

38. Sims, L.; Falkenberg, T. Developing Competencies for Education for Sustainable Development: A Case Study of Canadian Faculties of Education. Int. J. High. Educ. 2013, 2, 1-14. [CrossRef]

39. Block, M.; Braßler, M.; Orth, V.; Riecke, M.; Lopez, J.M.R.; Perino, G.; Tan, W.-H.; Lamparter, M. Dies Oecologicus-How to Foster a Whole Institutional Change with a Student-Led Project as Tipping Point for Sustainable Development At Universities. In Teaching Education For Sustainable Development at University Level; Leal Filho, W., Pace, P., Eds.; Springer: Berlin, Germany, 2016; pp. 341-355.

40. Lapkin, S.; Levett-Jones, T.; Gilligan, C. A Systematic Review of the Effectiveness of Interprofessional Education in Health Professional Programs. Nurse Educ. Today 2013, 33, 90-102. [CrossRef]

41. Matthews, K.E.; Firn, J.; Schmidt, S.; Whelan, K. A Comparative Study on Student Perceptions of Their Learning Outcomes in Undergraduate Science Degree Programmes with Differing Curriculum Models. Int. J. Sci. Educ. 2017, 39, 742-760. [CrossRef]

42. United Nations. n.d. Sustainable Development Goals. Available online: https://sustainabledevelopment.un. org/sdgs (accessed on 22 March 2019).

43. Sheehan, K.B. E-mail Survey Response Rates: A Review. J. Comput. Mediated Commu. 2001, 6. [CrossRef]

44. Barbour, R.S. Checklists for Improving Rigour in Qualitative Research: A Case of the Tail Wagging the Dog? Br. Med. J. 2001, 322, 1115-1117. [CrossRef] [PubMed]

45. Reid, R.; Bruce, D.; Allstaff, K.; Mclernon, D. Validating the Readiness for Interprofessional Learning Scale (RIPLS) in the Postgraduate Context: Are Health Care Professionals Ready for IPL? Med. Educ. 2006, 40, 415-422. [CrossRef] [PubMed]

46. Likert, R. A Technique for the Measurement of Attitudes. Arch. Psychol. 1932, 22, 5-55.

47. Geer, J.G. What do Open-Ended Questions Measure? Public Opin. Q. 1988, 52, 365-367. [CrossRef]

48. Alkaher, I.; Goldman, D. Characterizing the Motives and Environmental Literacy of Undergraduate and Graduate Students who Elect Environmental Programs: A Comparison Between Teaching-Oriented and Other Students. Environ. Educ. Res. 2018, 24, 969-999. [CrossRef]

49. Australian Bureau of Statistics. Australian Standard Classification of Education (ASCED). 2001. Available online: https://www.abs.gov.au/ (accessed on 22 October 2020).

50. Chan, Y.; Walmsley, R.P. Learning and Understanding the Kruskal-Wallis One-Way Analysis-Of-Variance-By-Ranks Test for Differences Among Three or More Independent Groups. Phys. Ther. 1997, 77, 1755-1761. [CrossRef]

51. Bewick, V.; Cheek, L.; Ball, J. Statistics Review 9: One-Way Analysis of Variance. Crit. Care 2004, 8, 130. [CrossRef]

52. Elo, S.; Kyngäs, H. The Qualitative Content Analysis Process. J. Adv. Nurs. 2008, 62, 107-115. [CrossRef]

53. Cook, D.A.; Artino, A.R., Jr. Motivation to Learn: An Overview of Contemporary Theories. Med. Educ. 2016, 50, 997-1014. [CrossRef]

54. Zeeni, N.; Zeenny, R.; Hasbini-Danawi, T.; Asmar, N.; Bassil, M.; Nasser, S.; Milane, A.; Farra, A.; Habre, M.; Khazen, G. Student Perceptions Towards Interprofessional Education: Findings from a Longitudinal Study Based in a Middle Eastern University. J. Interprof. Care 2016, 30, 165-174. [CrossRef] [PubMed]

55. Wilson, L.; Ho, S.; Brookes, R.H. Student Perceptions of Teamwork Within Assessment Tasks in Undergraduate Science Degrees. Assess. Eval. High. Educ. 2018, 43, 786-799. [CrossRef] 
56. Williams, B.; Boyle, M.; Brightwell, R.; Mccall, M.; Mcmullen, P.; Munro, G.; O’Meara, P.; Webb, V. A Cross-Sectional Study of Paramedics' Readiness for Interprofessional Learning and Cooperation: Results from Five Universities. Nurse Educ. Today 2013, 33, 1369. [CrossRef]

57. Keshtkaran, Z.; Sharif, F.; Rambod, M. Students' Readiness for and Perception of Inter-Professional Learning: A Cross-Sectional Study. Nurse Educ. Today 2014, 34, 991-998. [CrossRef] [PubMed]

58. Varsavsky, C.; Matthews, K.E.; Hodgson, Y. Perceptions of Science Graduating Students on Their Learning Gains. Int. J. Sci. Educ. 2014, 36, 929-951. [CrossRef]

59. Steinert, Y. Learning Together to Teach Together: Interprofessional Education and Faculty Development. J. Interprof. Care 2005, 19, 60-75. [CrossRef]

60. O'brien, K.; Selboe, E.; Hayward, B.M. Exploring Youth Activism on Climate Change. Ecol. Soc. 2018, $23,42$. [CrossRef]

61. Deloitte Global. The Deloitte Global Millennial Survey 2020: Resilient Generations Hold the Key to Creating a “Better Normal". 2020. Available online: https://www2.deloitte.com/global/en/pages/about-deloitte/articles/ millennialsurvey.html (accessed on 22 October 2020).

62. Brown, R.R.; Deletic, A.; Wong, T.H. Interdisciplinarity: How to Catalyse Collaboration. Nat. News 2015, 525, 315. [CrossRef]

63. Moslemi, J.M.; Capps, K.A.; Johnson, M.S.; Maul, J.; McIntyre, P.B.; Melvin, A.M.; Vadas, T.M.; Vallano, D.M.; Watkins, J.M.; Weiss, M. Training Tomorrow's Environmental Problem Solvers: An Integrative Approach to Graduate Education. BioScience 2009, 59, 514-521. [CrossRef]

64. Michalec, B.; Giordano, C.; Pugh, B.; Arenson, C.; Speakman, E. Health Professions Students' Perceptions of Their IPE Program: Potential Barriers to Student Engagement with IPE Goals. J. Allied Health 2017, 46, 10-20.

65. Weinberg, A.; Harding, C. Interdisciplinary Teaching and Collaboration in Higher Education: A Concept Whose Time has Come. Wash. Univ. J. Law Policy 2004, 14, 15.

66. Eastwood, J.L.; Schlegel, W.M.; Cook, K.L. Effects of an Interdisciplinary Program on Students' Reasoning with Socioscientific Issues and Perceptions of Their Learning Experiences. In Socio-Scientific Issues in the Classroom; Sadler, T.D., Ed.; Springer: Dordrecht, The Netherlands, 2011; pp. 89-126.

67. Tenenbaum, H.R.; Winstone, N.E.; Leman, P.J.; Avery, R.E. How Effective Is Peer Interaction in Facilitating Learning? A Meta-Analysis. J. Educ. Psychol. 2019, 112, 1303-1319. [CrossRef]

68. King, P.M.; Kitchener, K.S. Developing Reflective Judgment: Understanding and Promoting Intellectual Growth and Critical Thinking in Adolescents and Adults; Jossey-Bass: San Francisco, CA, USA, 1994.

69. Reynolds, M.; Trehan, K. Classroom as Real World: Propositions for a Pedagogy of Difference. Gend. Educ. 2001, 13, 357-372. [CrossRef]

70. Brophy, J.; Alleman, J. A Caveat: Curriculum Integration isn't Always a Good Idea. Educ. Leadersh. 1991, 49, 66.

71. Penny, S. Rigorous Interdisciplinary Pedagogy: Five Years of ACE. Convergence 2009, 15, 31-54. [CrossRef]

72. Hannon, J.; Hocking, C.; Legge, K.; Lugg, A. Sustaining Interdisciplinary Education: Developing Boundary Crossing Governance. High. Educ. Res. Dev. 2018, 37, 1424-1438. [CrossRef]

73. Barton, K.; Smith, L. Themes Or Motifs? Aiming for Coherence Through Interdisciplinary Outlines. Read. Teach. 2000, 54, 54-63.

74. Graves, M.F.; Braaten, S. Scaffolded Reading Experiences: Bridges to Success. Prev. Sch. Fail. Altern. Educ. Child. Youth 1996, 40, 169-173. [CrossRef]

75. Star, C.; Mcdonald, J. Embedding Successful Pedagogical Practices: Assessment Strategies for a Large, Diverse, First Year Student Cohort. Int. J. Pedag. Learn. 2007, 3, 18-30. [CrossRef]

76. Thistlethwaite, J. Interprofessional Education: A Review of Context, Learning and the Research Agenda. Med. Educ. 2012, 46, 58-70. [CrossRef]

77. Walker, L.E.; Cross, M.; Barnett, T. Students' Experiences and Perceptions of Interprofessional Education During Rural Placement: A Mixed Methods Study. Nurse Educ. Today 2019, 75, 28-34. [CrossRef] [PubMed]

78. Jutte, L.S.; Browne, F.R.; Reynolds, M. Effects of an Interprofessional Project on Students' Perspectives on Interprofessional Education and Knowledge of Health Disciplines. Athl. Train. Educ. J. 2016, 11, 189-193. [CrossRef]

79. Neville, C.C.; Petro, R.; Mitchell, G.K.; Brady, S. Team Decision Making: Design, Implementation and Evaluation of an Interprofessional Education Activity for Undergraduate Health Science Students. J. Interprof. Care 2013, 27, 523-525. [CrossRef] [PubMed] 
80. Kelly, M.A.; Hopwood, N.; Rooney, D.; Boud, D. Enhancing Students' Learning Through Simulation: Dealing with Diverse, Large Cohorts. Clin. Simul. Nurs. 2016, 12, 171-176. [CrossRef]

81. Campbell, J.; Li, M. Asian Students' Perceptions of Group Work and Group Assignments in a New Zealand Tertiary Institution. Intercult. Educ. 2006, 19, 203-216.

Publisher's Note: MDPI stays neutral with regard to jurisdictional claims in published maps and institutional affiliations.

(C) 2020 by the authors. Licensee MDPI, Basel, Switzerland. This article is an open access article distributed under the terms and conditions of the Creative Commons Attribution (CC BY) license (http://creativecommons.org/licenses/by/4.0/). 